\title{
Expression levels of resistant genes affect cervical cancer prognosis
}

\author{
FENGMEI YANG ${ }^{1 *}$, BO GAO $^{2 *}, \mathrm{RUI} \mathrm{LI}^{3}$, WENCUI LI ${ }^{2}$, WEI CHEN ${ }^{2}$, ZONGTAO YU $^{2}$ and JICAI ZHANG ${ }^{2}$ \\ Departments of ${ }^{1}$ Obstetrics and Gynecology, ${ }^{2}$ Laboratory Medicine and ${ }^{3}$ Infection Control, \\ Taihe Hospital, Hubei University of Medicine, Shiyan, Hubei 442000, P.R. China
}

Received January 23, 2016; Accepted January 31, 2017

DOI: $10.3892 / \mathrm{mmr} .2017 .6328$

\begin{abstract}
Tumor cells may develop multidrug resistance (MDR) to various chemotherapy regimens. Such resistance reduces the sensitivity of cells to chemotherapy drugs, leading to the failure of cervical cancer (CC) treatment and disease progression. The present study aimed to investigate the role of $M D R 1$, lung resistance protein $(L R P)$ and placental glutathione S-transferase $\pi 1$ (GSTPl) in CC and MDR, and the prognostic value of these genes. The mRNA expression levels of these resistance-associated genes were determined in $47 \mathrm{CC}$ and 20 healthy cervical tissue samples. Subsequently, the data was analyzed alongside clinicopathological parameters. The mRNA expression levels of MDRl, LRP and GSTP1 in CC were $0.57 \pm 0.32,0.58 \pm 0.29$ and $0.44 \pm 0.24$, respectively, whereas those in healthy cervical tissues were $0.19 \pm 0.10,0.17 \pm 0.14$ and $0.18 \pm 0.10$, respectively. Therefore, the expression levels of these genes were significantly greater in CC compared with healthy cervical tissue $(\mathrm{P}<0.05)$. mRNA expression levels of $M R D 1$ were increased in the well differentiated group $(0.68 \pm 0.27)$ compared with the poorly differentiated group $(0.38 \pm 0.33$; $\mathrm{P}<0.05)$. No significant differences were observed between LRP and GSTPI mRNA expression levels and tumor differentiation or clinical stage of the patients $(\mathrm{P}>0.05)$. Multivariate logistic regression indicated that the degree of differentiation and the $M D R 1$ gene expression levels were predictors of $\mathrm{CC}$ prognosis $(\mathrm{P}<0.05)$. The survival rate of patients in the $M D R l$-negative group was significantly greater compared with the $M D R 1$-positive group $(\mathrm{P}<0.05)$. The results of the present study therefore suggested that $M D R l$ gene expression is a predictor of poor survival in $\mathrm{CC}$.
\end{abstract}

\section{Introduction}

Cervical cancer (CC) is a common malignancy of the female reproductive system. In China, $>200,000$ fatalities due to CC

Correspondence to: Professor Jicai Zhang, Department of Laboratory Medicine, Taihe Hospital, Hubei University of Medicine, 32 South Renmin Road, Shiyan, Hubei 442000, P.R. China

E-mail: fromzero1121@hotmail.com

*Contributed equally

Key words: resistance gene, cervical cancer, expression, prognosis occur each year, and the incidence in younger age groups is on the increase (1). Current treatment approaches to CC include surgery, chemotherapy and radiotherapy in patients with primary tumors. However, due to continuous use of various chemotherapy drugs, multidrug resistance (MDR) may develop in tumor cells. Such resistance reduces the sensitivity of tumor cells to chemotherapy, leading to failure of treatment. MDR is defined as the resistance of cancer cells to a diverse panel of structurally and functionally unassociated drugs (2). This resistance can occur naturally (inherent resistance) or acquired during the course of chemotherapy (3). To date, current research on MDR has focused on the transcriptional regulation of the $M D R$ gene. The multidrug-resistance 1 (MDR1) gene product P-glycoprotein (P-gp) is an efflux pump that actively transports substrates, such as glucocorticoids, out of the cell (4). LRP is a small subcellular structure located at cytoplasmic vaults that may be in charge of subsequent exocytosis of agents from the cell. A previous in vitro study determined that LRP was associated with resistance to melphalan, cisplatin and doxorubicin (5). GSTP1, which has an important role in the detoxification of toxic substances, is a phase II metabolic enzyme, protects cells from anticancer drug-induced injury (6). To understand the role of the MDR gene in primary drug resistance, the present study detected the mRNA expression levels of MDR1, LRP and GSTP1 in 47 cases of $\mathrm{CC}$ and 20 healthy cervical tissue samples. In addition, a preliminary study on the association between the expression levels of these genes and cervical pathology was conducted. The present study investigated mechanisms underlying drug resistance in $\mathrm{CC}$ and may aid understanding of individual responsiveness to chemotherapy and prognosis.

\section{Materials and methods}

Patients and specimens. A total of 47 fresh CC specimens were collected from February 2008 to August 2010. Patients were aged between 43 and 65 years, with a mean age of 46.7 years. Histologic cell types included 41 cases of squamous-cell carcinoma and 6 cases of adenocarcinoma. Clinical staging was performed, and was as follows: Stage I, 12 cases; stage II, 18 cases; and stage III, 17 cases. Of these cases, 10 were well differentiated, 16 were moderately differentiated and 21 were poorly differentiated carcinomas. All diagnoses were confirmed by pathology. A total of 19 cases were $\geq 4 \mathrm{~cm}$ in size and 28 measured $<4 \mathrm{~cm}$. All patients had not received chemotherapy and radiation therapy prior to sample collection. In addition, 
20 healthy cervical tissue samples were collected (cancerous tissue from the same cervical margin tissue surgery measures $>2 \mathrm{~cm}$ from the edge, as the tumor edge was not clear, an additional 27 cases were not collected). Samples were stored in liquid nitrogen for future use. The integrity of clinical data was maintained, and the patients were monitored for 6 to 60 months.

RNA extraction and reverse transcription-quantitative polymerase chain reaction $(R T-q P C R)$. Total RNA was extracted from tissues using TRIzol ${ }^{\circledR}$ reagent (Thermo Fisher Scientific, Inc., Waltham, MA, USA) according to the manufacturer's protocol. The concentration and purity of total RNA was determined by measuring the absorbance with a NanoDrop-2000 spectrophotometer at wavelengths of 260 and $280 \mathrm{~nm}$. cDNA was synthesized from total RNA using the Reverse Transcription system (Promega Corporation, Madison, WI, USA) according to the manufacturer's protocol. cDNA was utilized immediately or stored at $-80^{\circ} \mathrm{C}$ until use. Each qPCR reaction contained $1.5 \mu \mathrm{l} 2 \mathrm{mmol} / \mathrm{l} \mathrm{dNTP}, 0.3 \mu \mathrm{l} 5 \mathrm{U} / \mu \mathrm{l} \mathrm{Taq}$ (Sangon Biotech Co., Ltd., Shanghai, China), $2.5 \mu 125$ mmol/l $\mathrm{Mg}^{2+}, 3 \mu \mathrm{l}$ 10X buffer, $2 \mu \mathrm{l}$ forward primer, $2 \mu \mathrm{l}$ reverse primer, $5 \mu \mathrm{l}$ cDNA $(0.5 \mu \mathrm{g} / \mu \mathrm{l}), 1.0 \mu \mathrm{l}$ 10X SYBR ${ }^{\circledR}$-Green I (Thermo Fisher Scientific, Inc., Waltham, MA, USA). The total volume of each reaction was adjusted to $30 \mu \mathrm{l}$ with sterile water. Cycling conditions were as follows: An initial predenaturation step at $94^{\circ} \mathrm{C}$ for $5 \mathrm{~min}$, followed by 35 cycles of denaturation at $95^{\circ} \mathrm{C}$ for $30 \mathrm{sec}$, annealing at $55^{\circ} \mathrm{C}$ for $30 \mathrm{sec}$ and extension at $72^{\circ} \mathrm{C}$ for $1 \mathrm{~min}$. Subsequently, dissociation curve analysis was performed, and the reaction products were separated by electrophoresis on a $2 \%$ agarose gel and stained with ethidium bromide for confirmation of the PCR products. The mRNA expression levels of $M D R 1, L R P$ and GSTP1 were expressed as a ratio relative to $G A P D H$ in each sample, the level of genes expression were normalized to that of the internal (GAPDH) and were determined by the $2^{-\Delta \Delta C q}$ method (7). Primer pairs were as follows: Forward, 5'-CCC ATC ATT GCA ATA GCA GG-3' and reverse, 5'-TGT TCA AAC TTC TGC TCC TGA-3' for human $M D R 1$; forward, 5'-CCA GAA CCA GGG AGG CAA GA-3' and reverse, 5'-GAG GCG CCC CAC ATA TGC T-3' for human GSTP1; forward, 5'-GTC TTC GGG CCT GAG CTG GTG TCG-3' and reverse, 5'-CTT GGC CGT CTC TTG GGG GTC CTT-3' for human $L R P$; and forward, 5'-GAA GGT GAA GGT CGG AGT C-3' and reverse, 5'- GAA GAT GGT GAT GGG ATT TC-3' for human GAPDH. MDR1, LRP, GSTP1 and GAPDH primers yielded products of 158, 325, 240 and $226 \mathrm{bp}$, respectively.

Statistical analysis. Statistical calculations were performed using SPSS software version 13.0 (SPSS, Inc., Chicago, IL, USA), and $\mathrm{P}<0.05$ was considered to indicate a statistically significant difference. The measured data were expressed as the mean \pm standard deviation. A Student's t-test, two-tailed chi-squared test and multivariate logistic regression analysis were used to compare groups. Survival curves were compared using the two-sided data log-rank method.

\section{Results}

mRNA expression levels of MDR1, LRP and GSTP1 in tissue samples. Of CC tissues, $63.8 \%$ were positive for $M D R 1,76.6 \%$ were positive for $L R P$ and $59.6 \%$ were positive for GSTP1. Of healthy tissues, $10 \%$ were positive for $M D R 1,15.0 \%$ were positive for $L R P$ and $5 \%$ were positive for GSTP1, compared with the healthy tissues, if the levels were $\geq 0.4$, the expression was deemed to be positive; otherwise, the expression was negative. Therefore, a greater percentage of CC tissues expressed these genes compared with healthy tissues $(\mathrm{P}<0.05)$. The relative mRNA expression levels of the resistance genes MDR 1, LRP and GSTP1 in cancer tissues were $0.57 \pm 0.32,0.58 \pm 0.29$ and $0.44 \pm 0.24$, respectively. The relative $\mathrm{mRNA}$ expression levels of $M D R 1, L R P$ and GSTP1 in normal cervical tissues were $0.19 \pm 0.10,0.17 \pm 0.14$ and $0.18 \pm 0.10$, respectively. Therefore, the mRNA expression levels of all three genes were greater in cancer compared with healthy cervical tissues, and this was statistically significant $(\mathrm{P}<0.001)$. In all cancer samples, the expression of all three genes was detected in 14 cases, expression of two genes was detected in 29 cases and expression of one gene was detected in 37 cases. MDR1, LRP and GSTP1 mRNA expression levels are presented in Fig. 1.

mRNA expression levels of MDR 1, LRP and GSTP1 and clinicopathological data. No significant differences were identified between the mRNA expression levels of LRP or GSTP1, and tumor size, histological type or clinical stage ( $P>0.05$; Table I). mRNA expression levels of $M D R l$ were significantly greater in poorly-differentiated compared with well and moderately differentiated carcinomas $(\mathrm{P}<0.05$; Table $\mathrm{I})$; however, no significant differences were identified between MDR1 mRNA expression and the other clinicopathological factors assessed.

mRNA expression levels of MDR-associated genes and survival rate of patients. Multivariate logistic regression analysis revealed that the risk factors of $\mathrm{CC}$ were associated with high mRNA expression levels of MDRl and the state of differentiation; however, there was no association between the mRNA expression levels of LRP or GSTP1 (data not shown), and tumor size or stage (Table II). The cancer samples were categorized into MDRl-positive $(\mathrm{n}=32)$ and -negative $(\mathrm{n}=15)$ groups. The survival rate was significantly greater in the $M D R$ l-negative group compared with the $M D R l$-positive group (Table II; Fig. 2; P<0.05)

\section{Discussion}

MDR may be divided into primary drug resistance that exists prior to chemotherapy treatment, and acquired drug resistance that may develop during chemotherapy. MDR was identified as an important factor that contributes to the failure of cancer treatment.

MDR is frequently associated with overexpression of the MDRl gene, which encodes the drug transporter, P-glycoprotein (P-gp). P-gp is one of the ABC transporter proteins that have similar trans-membrane domains that may pump chemotherapeutic drugs out of cancer cells against a concentration gradient in an ATP energy-dependent manner; therefore, reducing intracellular accumulation of chemotherapeutic agents and protecting cancer cells from toxicity (8). MDR1 genes and/or increased expression of P-gp have been associated with drug resistance (9-11). The glutathione (GSH) system is responsible for the detoxification of reactive oxygen 
Table I. Association between MDR1, LRP and GSTP1 mRNA expression levels and clinicopathological parameters in cervical cancer.

\begin{tabular}{|c|c|c|c|c|c|c|c|c|c|c|}
\hline Study groups & $\mathrm{n}$ & $M D R 1$ & $t$ & P-value & $L R P$ & $t$ & P-value & GSTP1 & $t$ & P-value \\
\hline \multicolumn{11}{|l|}{ Size (cm) } \\
\hline$\geq 4$ & 19 & $0.48 \pm 0.27$ & \multirow{2}{*}{-1.29} & \multirow{2}{*}{0.21} & $0.51 \pm 0.33$ & \multirow{2}{*}{-1.34} & \multirow{2}{*}{0.19} & $0.42 \pm 0.25$ & \multirow{2}{*}{-0.49} & \multirow{2}{*}{0.63} \\
\hline$<4$ & 28 & $0.62 \pm 0.34$ & & & $0.63 \pm 0.26$ & & & $0.46 \pm 0.24$ & & \\
\hline \multicolumn{11}{|l|}{ Histological type } \\
\hline Squamous carcinoma & 41 & $0.62 \pm 0.31$ & \multirow{2}{*}{1.72} & \multirow{2}{*}{0.1} & $0.60 \pm 0.29$ & \multirow{2}{*}{0.85} & \multirow{2}{*}{0.40} & $0.45 \pm 0.23$ & \multirow{2}{*}{0.14} & \multirow{2}{*}{0.89} \\
\hline Adenocarcinoma & 6 & $0.47 \pm 0.39$ & & & $0.49 \pm 0.30$ & & & $0.43 \pm 0.33$ & & \\
\hline \multicolumn{11}{|l|}{ FIGO stages } \\
\hline $\mathrm{I}+\mathrm{II}$ & 30 & $0.62 \pm 0.31$ & \multirow{2}{*}{1.53} & \multirow{2}{*}{0.13} & $0.58 \pm 0.31$ & \multirow{2}{*}{-0.069} & \multirow{2}{*}{0.94} & $0.47 \pm 0.24$ & \multirow{2}{*}{1.27} & \multirow{2}{*}{0.21} \\
\hline III & 17 & $0.46 \pm 0.32$ & & & $0.58 \pm 0.28$ & & & $0.38 \pm 0.25$ & & \\
\hline \multicolumn{11}{|l|}{ Differentiation } \\
\hline Well+moderately & 26 & $0.68 \pm 0.27$ & \multirow{2}{*}{3.16} & \multirow{2}{*}{0.003} & $0.61 \pm 0.29$ & \multirow{2}{*}{0.71} & \multirow{2}{*}{0.49} & $0.47 \pm 0.25$ & \multirow{2}{*}{0.70} & \multirow{2}{*}{0.50} \\
\hline Poorly & 21 & $0.38 \pm 0.33$ & & & $0.54 \pm 0.29$ & & & $0.42 \pm 0.23$ & & \\
\hline
\end{tabular}

Gene expression data are expressed as the mean \pm standard deviation. MDR, multidrug resistance; LRP, lung resistance protein; GSTP1, placental glutathione S-transferase $\pi$; FIGO, The International Federation of Gynecology and Obstetrics.

Table II. Multivariate logistics analysis on factors that influence cervical cancer prognosis.

\begin{tabular}{lcccc}
\hline Covariates & Deceased patients/total & B & Exp (B) & 95\% CI \\
\hline Differentiation & & & 16.89 & $1.71-166.48$ \\
Well+moderately & $6 / 26$ & 2.83 & & 0.015 \\
Poorly & $8 / 21$ & & 38.53 & $3.03-490.35$ \\
MDR1 & $12 / 32$ & 3.65 & 0.005 \\
Positive & $2 / 15$ & & & \\
Negative & & & \\
\hline
\end{tabular}

MDR1, multidrug resistance 1; B, regression coefficient; Exp (B), odds ratio; CI, confidence interval.
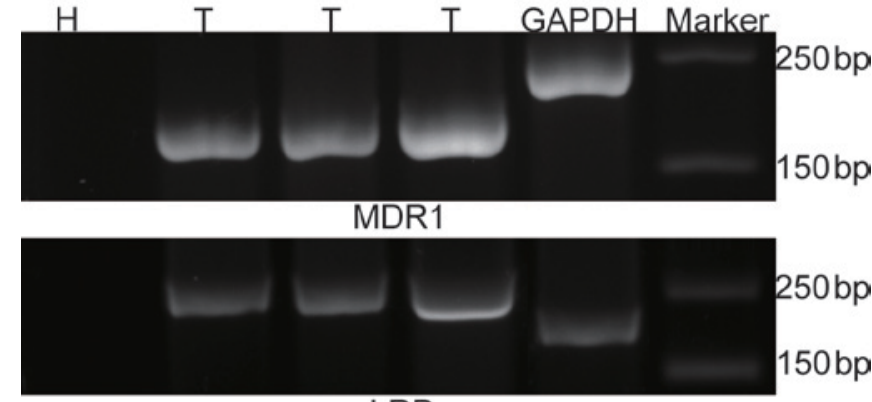

$250 \mathrm{bp}$

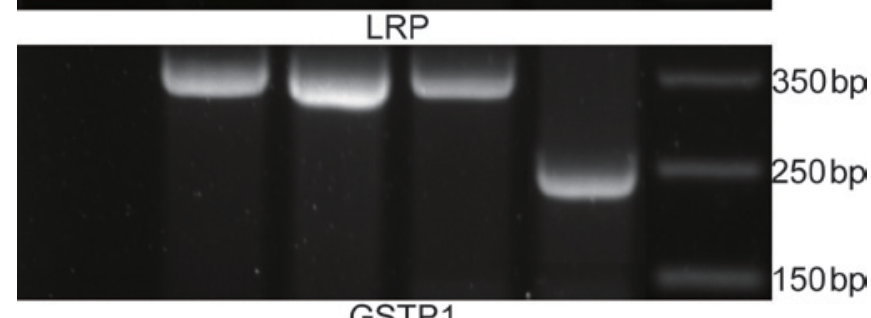

GSTP1

Figure 1. mRNA expression levels of MDR1, LRP and GSTP1 in normal and cervical cancer tissue specimens. MDR1, multidrug resistance 1; LRP, lung resistance protein; GSTP1, placental glutathione S-transferase $\pi$; $\mathrm{H}$, healthy; $\mathrm{T}$, cervical cancer tissue.

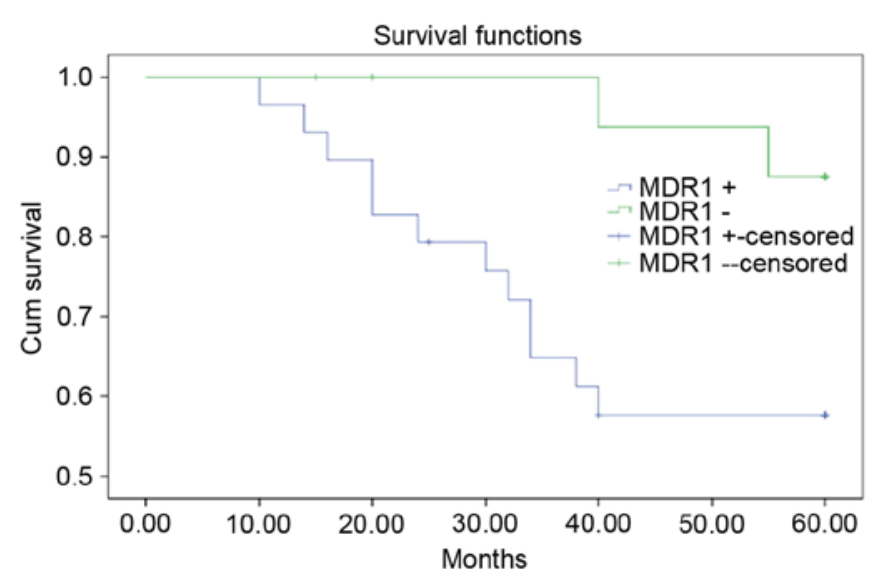

Figure 2. Survival curves of $M D R 1$-positive $(\mathrm{n}=32)$ and $M D R 1$-negative $(\mathrm{n}=15)$ patients. $\mathrm{P}<0.05 . M D R 1$, multidrug resistance 1.

and nitrogen species in cells. Tumor cells that express glutathione s-transferase (GST) may catalyze the conjugation of GSH to anticancer drugs, which are subsequently removed 
from the cell by transporters. This protects cells from anticancer drug-induced injury. GST expression is primarily induced by alkylating agents, including platinum compounds and mitomycin-c (12). LRP serves a role in drug resistance in breast cancer (13), ovarian cancer (14), lung cancer (15) and various other tumor types. Enhanced expression levels of LRP may cause tumor cells to become resistant to traditional chemotherapy drugs, including doxorubicin, cisplatin, vincristine and mitomycin (16). Therefore, findings regarding the expression of LRP revealed that cervical cancer has an intrinsic resistance of cisplatin (17). In the present study, the mRNA expression levels of the resistance genes $M D R 1$, $L R P$ and GSTPl were measured in cancer tissue specimens and compared with clinicopathological data, to investigate their role in primary drug resistance in cancer. Tolerance of tumor cells to drugs is associated with the expression levels of drug resistance genes in cells. Therefore, the expression levels of drug resistance genes indirectly reflect the resistance of tumor cells to drugs. The present study demonstrated that the mRNA expression levels of MDR1,LRP and GSTP1 in CC tissue specimens were greater compared with healthy cervical tissues. Patients had not received chemotherapy or radiation therapy. This suggested that primary drug resistance was associated with CC.

In the present study, not all tumors expressed the MDR-associated genes; $29.8 \%$ of tumors expressed $M D R 1$, LRP and GSTP1, and $61.7 \%$ expressed two of these genes. This suggested that the expression levels of these genes in CC are regulated by signaling pathways that contribute to MDR, which are likely exhibit a high degree of complexity and interconnectivity.

The mRNA expression levels of $M D R l$ were greater in well and moderately differentiated carcinomas compared with poorly differentiated carcinomas, which suggested that the greater the degree of cancer differentiation, the greater the resistance to chemotherapeutic drugs. However, the mRNA expression levels of LRP and GSTPI in the tumor tissues did not exhibit a significant association with the clinicopathological features of the patients. Greater numbers of specimens would be necessary to confirm this finding. High mRNA expression levels of $L R P$ and GSTPI may mediate drug resistance of tumor cells to cisplatin, suggesting that primary MDR of $C C$ to cisplatin may be associated with the expression levels of LRP and GSTPl genes (18).

Sato et al (19) demonstrated that high expression levels of P-gp were detected in lymph node metastasis of the colon. In a follow-up study of 112 patients with CC, Nagai et al (20) revealed that the five-year survival rate of $\mathrm{P}$-gp-positive patients was significantly reduced compared with patients with P-gp-negative tumors. In the present study, high MDRI mRNA expression levels were associated with poor CC survival rates, suggesting that $M D R l$ may be a high-risk prognostic factor.

Reducing the expression levels of genes associated with drug resistance is likely to enhance the efficacy of therapy. The expression levels of the MDRl gene and its corresponding protein, P-gp, were significantly reduced in cancer cells transfected with small interfering RNA targeting MDR1 (21). In vitro experiments and RNA interference technology may effectively reverse drug resistance in ovarian cancer cells (22).
Studies that aim to reverse drug resistance in solid tumors warrant further investigation.

In conclusion, MDR I, LRP and GSTP1 genes may be involved in mechanisms underlying primary MDR in CC. Detection of MDR1 expression levels may be utilized to predict patient response to chemotherapy. Reversal of CC drug resistance may strengthen the efficacy of chemotherapy and prolong the survival of patients with $\mathrm{CC}$.

\section{References}

1. Aggarwal P: Cervical cancer: Can it be prevented? World J Clin Oncol 5: 775-780, 2014.

2. Fojo A, Hamilton TC, Young RC and Ozols RF: Multidrug resistance in ovarian cancer. Cancer 60 (8 Suppl): S2075-S2080, 1987.

3. Gong J, Jaiswal R, Mathys JM, Combes V, Grau GE and Bebawy M: Microparticles and their emerging role in cancer multidrug resistance. Cancer Treat Rev 38: 226-234, 2012.

4. Lage H: Gene therapeutic approaches to overcome ABCB1Mediated drug resistance. Recent Results Cancer Res 209: 87-94, 2016.

5. Izquierdo MA, Shoemaker RH, Flens MJ, Scheffer GL, Wu L, Prather TR and Scheper RJ: Overlapping phenotypes of multidrug resistance among panels of human cancer-cell lines. Int J Cancer 65: 230-237, 1996

6. Wu L, Shen Y, Peng X, Zhang S, Wang M, Xu G, Zheng X, Wang $J$ and Lu C: Aberrant promoter methylation of cancer-related genes in human breast cancer. Oncol Lett 12: 5145-5155, 2016.

7. Karabulut S, Kaya Z, Amuran GG, Peker I, Özmen T, Gūllūoḡlu BM, Kaya H, Erzik C, Ōzer A and Akkiprik M: Correlation between the DNA methylation and gene expression of IGFBP5 in breast cancer. Breast Dis 36: 123-131, 2016.

8. Dong $X$ and Mumper RJ: Nanomedicinal strategies to treat multidrug-resistant tumors: Current progress. Nanomedicine (Lond) 5: 597-615, 2010.

9. Li WT, Aizimu A and Wang YH: Relationship between the expression of P-glycoprotein and the therapeutic effect of neoadjuvant chemotherapy on Uygur and Han patients with cervical cancer. J Chin Pract Diagn Ther 25: 225-227, 2011.

10. Tydén E, Skarin M and Höglund J: Gene expression of ABC transporters in Cooperia oncophora after field and laboratory selection with macrocyclic lactones. Mol Biochem Parasitol 198: 66-70, 2014.

11. Zhang Q, Wang J, He H, Liu H, Yan X and Zou K: Trametenolic acid $\mathrm{B}$ reverses multidrug resistance in breast cancer cells through regulating the expression level of P-glycoprotein. Phytother Res 28: 1037-1044, 2014.

12. Stewart DJ: Tumor and host factors that may limit efficacy of chemotherapy in non-small cell and small cell lung cancer. Crit Rev Oncol Hematol 75: 173-234, 2010.

13. Wood N and Streckfus CF: The expression of lung resistance protein in saliva: A novel prognostic indicator protein for carcinoma of the breast. Cancer Invest 33: 510-515, 2015.

14. Lu D, Shi HC, Wang ZX, Gu XW and Zeng YJ: Multidrug resistance-associated biomarkers PGP, GST- $\pi$, Topo-II and LRP as prognostic factors in primary ovarian carcinoma. $\mathrm{Br} \mathrm{J}$ Biomed Sci 68: 69-74, 2011.

15. Li YJ, Yu CH, Zhang W, Liu Y and Liu Y: The relationship between expression of COX-2'LRP and metastasis and prognosis in patients with non-small cell lung carcinoma. J Clin Pulm Med 15: 1707-1709, 2010.

16. Jiao JW and Wen F: Tanshinone IIA acts via p38 MAPK to induce apoptosis and the down-regulation of ERCC1 and lung-resistance protein in cisplatin-resistant ovarian cancer cells. Oncol Rep 25: 781-788, 2011.

17. Zhong H, Zuo Y, Wu X, Peng Y, He H, Yang J, Guan C and $\mathrm{Xu} \mathrm{Z}$ : Synergistic antitumor effect of amorphigenin combined with cisplatin in human lung adenocarcinoma A549/DDP cells. Zhongguo Fei Ai Za Zhi 19: 805-812, 2016 (In Chinese).

18. Daukantienė L, Kazbarienė B, Valuckas KP, Didžiapetrienė J, Krikštaponienè A and Aleknavičius E: The significance of reduced glutathione and glutathione S-transferase during chemoradiotherapy of locally advanced cervical cancer. Medicina (Kaunas) 50: 222-229, 2014. 
19. Sato A, Shimada K, Nakamachi M, Ushio J, Yamamoto W, Kurihara $\mathrm{M}$ and Matsukawa M: Effectiveness of doxifluridine (5'-DFUR)/docetaxel against advanced/recurrent gastric cancer showing resistance to various anticancer drug regimens. Gastric Cancer 5: 233-236, 2002.

20. Nagai N1, Shiroyama Y, Oshita T, Mukai K, Shigemasa K, Fujii T, Katsube Y, Matsubayashi S, Murakami T and Ohama K: Tumor dihydropyrimidine dehydrogenase activity in advanced cervical carcinoma. Oncol Rep 9: 1033-1040, 2002.
21. Lou JY, Peng ZL, Zheng Y, Wang H, He B and Wang HJ: Reversal of multi-drug resistance in ovarian cancer cell by RNA interference. Zhonghua Fu Chan Ke Za Zhi 41: 413-416, 2006.

22. Gao GL, Tu KJ and Liu FJ: Expression and reversal of multi-drug resistance gene in ovarian cancer. Chin Clin Oncol 15: 870-873, 2010 . 